\title{
The Competence-Based Advanced Level Mathematics Curriculum: Implications for Students' Enrolment in one University in Zimbabwe
}

DOI: https://doi.org/10.47175/rielsj.v2i1.194

\begin{tabular}{|c|c|}
\hline Namatirai Chikusvura $^{1}$ & Lwazi Sibanda² | Joyce Mathwasa ${ }^{3}$ | \\
\hline $\begin{array}{l}\text { 1,2Department of Science, } \\
\text { Mathematics and Technology } \\
\text { Education, National University } \\
\text { of Science and Technology, } \\
\text { Bulawayo, Zimbabwe } \\
{ }^{3} \text { School of General and } \\
\text { Continuing Education (SGCE), } \\
\text { University of Fort Hare, East } \\
\text { London, South Africa. } \\
\\
{ }^{1} \text { nchikusvura@gmail.com, } \\
{ }^{2} \text { Iwazi.sibanda@nust.ac.zw, } \\
{ }^{3} \text { jmathwasa1@gmail.com } \\
\text { Corresponding E-mail: } \\
\text { Iwazi.sibanda@nust.ac.zw }\end{array}$ & $\begin{array}{l}\text { ABSTRACT } \\
\text { The study set out to examine the relevance of the competence- } \\
\text { based Advanced Level mathematics curriculum for entry into } \\
\text { university mathematics-related degree programmes. The study } \\
\text { adopted a qualitative approach ingrained in the interpretive } \\
\text { paradigm which employed a case study design. Four A-Level } \\
\text { mathematics teachers, eighteen Lower Sixth and six Upper Sixth } \\
\text { mathematics major students were purposively sampled to respond } \\
\text { to semi-structured face-to-face interviews and focus group } \\
\text { interviews. The study found that the implementation of the } \\
\text { competence-based Advanced Level mathematics curriculum was } \\
\text { negatively affected by incompetent teachers and supervisors, lack } \\
\text { of resources and lack of support fromother stakeholders. The study } \\
\text { concluded that these impediments impacted negatively on } \\
\text { students who aspired to pursue mathematics-related degree } \\
\text { programmes at university and that there is a mismatch on the } \\
\text { mathematics units in the competence-based Advanced Level } \\
\text { mathematics curriculum and university requirements for } \\
\text { mathematics-related degree programmes. The study recommends } \\
\text { ministerial corroboration fostering university degree programmes } \\
\text { requirements to be taught in high school, stakeholder involvement } \\
\text { and continuous professional development for mathematics } \\
\text { teachers and supervisors. } \\
\text { KEYWORDS } \\
\text { competence-based Advanced Level mathematics curriculum; } \\
\text { implementation; mathematics units; student enrolment; } \\
\text { university mathematics-related degree programmes }\end{array}$ \\
\hline
\end{tabular}

\section{INTRODUCTION}

In any education system, a change in the curriculum comes with some new expectations for both teachers and students since they are the key implementers and recipients, respectively. Ever since the replacement of traditional, knowledge-based curricular by new competencebased curricular in countries such as the United States of America, the United Kingdom, Canada, Australia and New Zealand, discourses have developed among academics and the general public on the expediency of these changes (Hourigan \& O'Donoghue, 2007). The argument is that students should be familiar with the type of curriculum they are exposed to if they are to be prepared for university. Hence, it is necessary to create a high school mathematics curriculum that has a good chance of providing students with the knowledge and skills that are needed to ensure success at university and career lives (James, 2016). This suggests that the selection of Advanced Level (A-Level) subjects must have a long-lasting influence when it comes to its application in universities (Kulshishtha, 2016). According to Darlington and Bowyer (2016) the Advanced Level subjects should meet the needs of 
prospective undergraduate mathematics students, as well as those intending to study subjects such as accounting, applied mathematics, biology, or civil engineering. In their study in Australia, Nicholas, Poladian, Wilson, and Mack (2015) concluded that mathematics preparation for university has always considered secondary school mathematics as central for entry into university science degrees. Henceforth, the preparedness of students enrolling into university is based on their ability in the high school mathematics curriculum.

However, Esau and Mpofu (2017) point out that in Georgia and Armenia, there is a massive gap between the level of technical competencies of school graduates and the requirements they face once they enrol in universities. This gap has emerged as a result of the differences in reforms of secondary and higher education in these countries. Similarly, in South Africa the introduction of outcomes-based curricular initiated a discourse on the preparedness of first-year students for programmes with mainstream mathematics. Thus, lecturers have increasingly become aware of first-year students' lack of understanding of fundamental mathematical concepts (Froneman \& Hitge, 2019). Some students have resorted to completely changing their intended degree programmes due to lack of appropriate mathematical background which should have been covered at A-Level (Makanda \& Sypkens, 2017).

In Zimbabwe, the Primary and Secondary Education curriculum has undergone various changes since independence in 1980. The current competence-based curriculum aims to promote and cherish the Zimbabwean identity, prepare students for life and work in a largely agro-based indigenised economy on an increasingly globalised and competitive environment, foster life-long learning in line with opportunities and challenges of society, prepare learners for participatory citizenship, peace and sustainable development (Ministry of Primary and Secondary Education, 2015). However, the advent of competence-based Advanced Level (A-Level) mathematics curriculum brought about varying perceptions on the nature of the seemingly new curriculum which marked an end to mathematics being taught as a double major. Teachers and students were to interact with a new approach to Advanced Level mathematics curriculum due to a split of the curriculum into independent units. Bell, Malacova and Shannon (2005) observe that the most offered mathematics unit(s) by high schools is influenced by the entry requirements to science-based degrees at university. This means that some students' options may be restricted, causing them to specialise out of necessity rather than through choice. Vidal Rodeiro (2007) affirms that while policy emphasis is on increasing choice for all students, the choice is limited for some of them. Sometimes students choose subjects not based on the preferred course, but on whether or not the school offers it. Hence, the issue of offering only one unit of mathematics in some schools has since contributed to some students only registering one option of the mathematics units in the final examinations. There is evidence that some students compromise their subject choices by tailoring their options to what the schools offer (Vidal Rodeiro, 2007).

Furthermore, concerns have been raised by educators, students, parents and other stakeholders through media regarding the enrolment at universities. It emerged that universities still require A-Level Pure Mathematics as their first preference when enrolling students for undergraduate degrees, rendering other mathematics units such as Statistics and Mechanical Mathematics worthless of studying at A-Level. The degree programmes which require Statistics are still limited leading to high schools preferring to offer Pure Mathematics only although it is not a full package of mathematics. It is, therefore, in the interest of the researchers to examine how teachers and students perceive the implications of competence-based Advanced Level mathematics curriculum on students' enrolment in one university in Zimbabwe. 


\section{RESEARCH METHODS}

The study was ingrained in the interpretive paradigm which adopted a qualitative approach and employed a case study design. This approach allowed experiences, opinions and attitudes of participants to be explained in depth. Participants expressed varied and multiple experiences and their meanings (Cohen, Manion \& Morrison, 2011). Purposively sampled participants comprised four A-Level mathematics teachers, eighteen Lower Sixth and six Upper Sixth mathematics major students in one secondary school in Bulawayo Metropolitan Province. Semi-structured face-to-face interviews were administered to A-Level mathematics teachers; focus group interviews were held with A-Level students majoring in at least one mathematics unit. Data were thematically presented and analysed (Kulbir, 2014; Mack, 2010). The issues of credibility and trustworthiness were taken into consideration through member checking in this study. The researchers were also conscious of the ethical issues of informed consent, protection from harm, privacy and confidentiality, as well as honesty in conducting the study. The codes such as T1-4 (Teachers), LFG (Group interview for Lower Sixth students) and UFG (Focus Group interview for Upper Sixth students) were used to conceal the identity of the participants

\section{RESULTS AND DISCUSSION}

\section{Factors that influence the implementation of the competence-based Advanced Level mathematics curriculum in view of students' enrolment at university}

There are varying factors that to be considered in a curriculum reform if desired outcomes are to be realised. In this vein, the introduction of the competence-based A-Level mathematics curriculum was met with diverse perceptions from teachers and students. The study sought to establish the factors that influence implementation of the aforementioned curriculum. Participants' responses are presented in the succeeding sub-headings.

\section{Availability of resources}

The availability of resources is crucial in the success of the implementation of the curriculum in any educational institution. The participants were asked to give their perceptions on how the availability or none-availability of resources impacted on the implementation of the competence-based A-Level mathematics curriculum regarding the students' enrolment at university. The responses were as follows:

T2: There are no resources and this negatively effects the implementation of the curriculum to a greater extent. For instance, some of the topics in the competencebased A-Level mathematics curriculum are not there in the old textbooks we are using. In this case, when teaching the topics like proof by induction and groups in Pure Mathematics, I rely on my personal notes and internet.

T4: If resources were available, set standards would be achieved. However, at our school we have limited resources and this affects my effectiveness as an A-Level teacher. I expect my students to excel at A-Level so that they are enrolled at university. But lack of resources does not motivate me to do my work whole-heartedly and I am not be able to achieve set goals.

LFG3: As learners we need textbooks so that we can read on our own during study time, we cannot rely on teachers only. 
Furthermore, participants were asked on resource mobilisation efforts done by the school for the implementation of the competence-based Advanced Level mathematics curriculum. The responses were:

LFG2: There is not much done by the school as teachers have to improvise.

T2: I can say it is zero since the competence-based A-Level mathematics curriculum was introduced, no new textbooks were bought, and we still use old textbooks and personal notes which we compile as we research for the lessons using other sources.

Basically, various stakeholders including parents usually assist in resource mobilisation in schools. When asked concerning the involvement of stakeholders in resource mobilisation, the students (LFG1, LFG2, LFG3 and UFG) appreciated the effort made by their parents and guardians in creating enabling learning environment through provision of learning resources. The teachers (T1, T3, and T4) further confirmed students' sentiments that:

Some parents are trying to provide learning resources for their children because most of the A-Level learners have smartphones and laptops. Some students have internet at home. This helps some of the students to access e-resources as a result they share with those who do not have access to internet.

From the responses, it is worth noting that although the school understudy is inadequately resourced, some parents as major stakeholders are making an effort to provide learning resources such as smartphones, laptops, and internet connectivity for their children, which helps students to access e-resources. However, it came out that not all parents are able to support the implementation of competence-based A-Level mathematics curriculum through provision of smartphones, laptops, and internet connectivity.

\section{Teacher Competences}

Participants were asked if teachers were competent enough to implement the competencebased A-Level mathematics curriculum making students ready for enrolment at university. Below are some of the responses from the participants:

T2: I am equipped but the issue of deployment does not match my expertise, I specialised in Pure Mathematics but I am teaching Statistics so far.

T4: Not to teach all the units, but I am adequately equipped in Statistics and Pure Mathematics. In Mechanics, I just did a part at A-Level and I never pursued Mechanics again so I still have some challenges in teaching Mechanics.

$\mathrm{T} 1$ and T3 were in agreement that their qualifications met the demands of the implementation of the competence-based A-Level mathematics curriculum. In agreement, the students had this to say:

LFG1: Teachers are okay, I would say they are very competent and do their best.

UFG: Teachers are competent although sometimes they are very fast in order to cover the syllabus.

Furthermore, the participants were asked how the teachers' competence influences the implementation of the competence-based Advanced Level mathematics curriculum regarding students' enrolment at university. Participants' responses were: 
T4: You cannot teach a mathematics curriculum unit that you are not competent in. You will lack confidence in yourself. Teachers must be competent enough to be able to implement the competence-based mathematics curriculum. I am not competent to teach Mechanics because I do not know the subject content. Also, we lack in-service training for us to effectively implement the curriculum.

Participants were also asked to give their opinion on measures that can be adopted to enable them to embrace the competence-based A-Level mathematics curriculum. In response the participants mentioned that:

T2: Deployment must be correlated to teacher competences. School leaders should finance and facilitate workshops, Olympiads and use resource teachers to assist other teachers as well as learners in areas of need. More Information and Communication Technology tools should be mobilised and the school should have rooms allocated specifically as mathematics resource centres. Supervisors should also be knowledgeable in the subject content.

On the same issue, T3 advanced that: It is better to merge the different units in the competence-based A-Level mathematics curriculum and have one syllabus that will cover all the concepts and competences. All experiences in life need all the different units.

It is evident from the responses that successful curriculum implementation depends on the competence of teachers and supervisors. Presented data indicate that some teachers in the selected school were not competent to teach all the mathematics units in the new curriculum but the units they specialised in during their teacher training. The participants also highlighted the need for in-service training for teachers to acquaint them with the requisite competences needed to effectively implement the competence-based A-Level mathematics curriculum. It also emerged that deployment in the mathematics department was not correlated to the teacher's area of specialisation for successful competence-based curriculum implementation to be achieved. The presented information suggests that the competences of teachers in the school understudy negatively affect students' enrolment at university.

\section{Students' self-perception}

Whenever there is change of curriculum, students tend to be sceptical. Hence, there is need for guidance so that students maintain a positive self-perception. To this effect, participants were asked to comment on the guidance received by students towards making choices for A-level mathematics combination in relation to enrolment at university. In this regard, the teacher participants confirmed that students are given career guidance before going into ALevel as well as before university entry. It was mentioned that students are advised on the importance of subject combination that are required for their intended university programmes.

LFG1 and UFG professed to have been guided by research and guardians or parents while T1, T3 and T4, LFG2 and LFG3 claimed that career guidance sessions were conducted at the school.

The participants were also asked to state whether students consult before settling for an A-Level subject combination. It turned out that not all students were given guidance in subject combination that would be relevant for pursuit of university programme but according to $\mathrm{T} 1$ and $\mathrm{T} 4$ only those students that consulted them were offered career guidance. T4 further advanced that: 
I first ask the students their passions before advising them on which A-Level mathematics units they should study in line with what they aspire to study at the university. But I also advise them that taking two units is advantageous to them.

The participants were further asked how beneficial the assistance was in selecting units of study in the competence-based A-Level mathematics curriculum. Some of the participants had this to say:

T1: It is beneficial since the students have to choose units that are directly linked to their intended degree programmes. When they clearly understand the requirements of the intended programme to pursue they tend to be self-driven thereby making it easy to successfully implement the competence-based A-Level mathematics curriculum.

LFG1: The way the curriculum is designed simplifies things for students who do not want to do Pure Mathematics but want to do Statistics only. However, regardless of the pressure one may face, it is necessary to do more than one unit for one to be at an advantage when enrolling at university.

Conversely, T2 held that:

Students are just like some sheep following a shepherd. They do not know what this curriculum intends. The perceptions of teachers directly influence the perceptions of students while in some students peer perceptions overrides the teacher's advice.

It emerged from the data that students appreciate the competence-based A-Level mathematics curriculum. Data also revealed that students received career guidance and consultations from former university students as well as from parents/guardians and teachers in choosing competence-based A-Level mathematics curriculum units that are related to their intended university degree programmes and career aspirations. Furthermore, the participants felt that studying more than one competence-based A-Level mathematics units was advantageous when it comes to enrolment into mathematics-related degree programmes at university.

\section{The effects of competence-based Advanced Level mathematics curriculum on university mathematics-related programmes}

The participants' views were sought on how the competence-based A-Level mathematics curriculum influenced the selection of university mathematics-related programmes. The data in this section were presented in the following sub-headings: students' enrolment at university, lack of fundamental mathematics concepts and students' achievements at university.

\section{Students' enrolment at university}

When asked whether all mathematics units are equally treated for students' enrolment at university, participants had this to say:

T1: No, I do not think so. For example, Pure Mathematics, Statistics and Mechanical Mathematics are viewed as different subjects at university.

T4: I do not think they are equally considered because universities usually advertise their degree programmes requirements as Pure Mathematics and Statistics and/or Mechanical Mathematics. However, universities are only considering Pure Mathematics as the most preferred unit. 
UFG: They should be treated differently since Pure Mathematics is more difficult.

Probing further, students were asked if the competence-based A-Level mathematics units they chose put them at an advantage regarding university enrolment. Their responses were:

LFG2: The points that I get at A-Level are all that matters although an extra A-Level mathematics unit is an advantage.

LFG3: I will be at an advantage since I am studying two mathematics units.

UFG: Yes, since Statistics is needed in all degree programmes.

Participants confirmed that the university considers Pure Mathematics as the most preferred A-Level mathematics unit when enrolling students in mathematics-related degree programmes. Other competence-based A-Level mathematics curriculum units are treated as added advantage. It was also revealed that students study A-level subjects they perceive to be advantageous for university enrolment.

\section{Lack of fundamental mathematics concepts}

For every curriculum to be valued and accepted it should have some fundamental concepts embedded in it. Such should be the case with the competence-based A-Level mathematics curriculum. The university selection criteria when enrolling students in mathematics related programmes is based on these fundamental mathematics concepts. Hence, the participants were asked whether or not it was ideal for universities to revise their selection criteria when enrolling students into university considering the current competence-based A-Level mathematics curriculum. The participants reacted as follows:

T1: Universities should revise their students' selection criteria but I believe this was considered before changing the curriculum.

T4: They have to consider that because if you check someone who does Pure Mathematics at A-Level has a wider selection at undergraduate yet someone who has done Statistics, selection will be limited. So, they need to review the selection criteria giving all mathematics units an equal weight.

LFG2: The universities should specify the benefits of studying Pure Mathematics together with other mathematics unit.

When asked whether students should study all the three mathematics units, T2 mentioned that:

They have to study all the units although we teachers are advocating for the maintenance of the old curriculum.

Considering the above information presented, it seems the students who do not study Pure Mathematics at A-Level have a challenge at university when they want to enrol for undergraduate mathematics related programmes. This suggests that the competence-based A-Level mathematics curriculum does not match the university selection criteria for entry into undergraduate mathematics related programmes.

\section{Students' achievements at university}

Participants were asked to clarify how students' A-Level mathematics unit(s) choices affect their university achievements. In response, teacher participants were of the view that those having one A-Level mathematics unit will be somewhat affected, firstly because they have 
limited degree programmes to choose from and they may lack some mathematics fundamentals embedded within the degree programmes they would have opted to study. For example, T1 explained:

It will affect their grades at university since their performance will be affected, obviously it will not be like someone who would have done all units at A-Level.

UFG: Nothing beats hard-work when one is at university.

The participants' responses revealed that studying more than one competence-based Advanced Level mathematics curriculum units add advantage for university entrance but hard work is essential for successful achievement at university.

\section{Challenges faced by high schools in implementing the competence-based Advanced Level mathematics curriculum}

Like with any curriculum, challenges arise when implementing the competence-based Advanced Level mathematics curriculum. Participants were requested to give an insight on challenges they encountered during the implementation of the competence-based Advanced Level mathematics curriculum regarding enrolment at university. In response the participants highlighted the following:

LFG1: We do not have enough time to study all mathematics units. Sometimes our timetable stretches to late hours, hence this might affect our performance in mathematics.

T2: Some students do not qualify to do A-Level mathematics but they enrol hoping to make it, these struggle with the subject. Scarcity of resources limits teachers in lesson delivery and adds a burden that frustrates teachers as they try to mobilise the resources to ensure the school achieved desired results. Teacher - student ratio is also a challenge as classes are too big. The other challenge is that not all parents can afford buying smartphones, laptops, and internet services for their children which in turn negatively affects students' performance in the new mathematics curriculum.

T4: Some students are not doing all units due to the nature of the curriculum, so it is difficult to help every student with baseline knowledge needed for university entrance.

Participants have revealed a myriad of challenges such as a congested timetable that does not permit students to effectively study all mathematics units required for university entrance; the high teacher-student ratio making it difficult for teachers to adequately prepare all students for university enrolment and inadequate resources thereby negatively affecting the implementation of the competence-based Advanced Level mathematics curriculum.

\section{Discussion}

The study established that although the school understudy is inadequately resourced, parents as major stakeholders made an effort to provide learning resources for their children. However, not all parents were able to afford those essential gadgets such as smartphones, laptops and internet connectivity so that students can access e-resources for the implementation of competence-based A-Level mathematics curriculum in preparation for university education. The findings of the current study confirm what Zhuwau and Shumba (2018) found in Nyanga North Area of Zimbabwe where it was revealed that availing 
sufficient resources in terms of textbooks and other learning materials in schools contribute to successful curriculum implementation.

The study found that teachers' and supervisors' competence was key to successful curriculum implementation. The findings of this study indicate that some teachers in the selected school were not competent to teach all the mathematics units in the said curriculum as in their training they specialised in one unit. It emerged that there was need for in-service training for teachers to familiarise them with the requisite competences needed to effectively implement the competence-based A-Level mathematics curriculum. Similarly, Wesselink (2010) observes that the introduction of competence-based education has an impact on the roles and corresponding tasks of teaching professionals hence the need for in-service training. Additionally, a study in Tanzania by Makunja (2016) also showed that the lack of in-service training limits the teachers' pedagogical knowledge to apply competence-based curriculum approaches during the teaching and learning process. It also emerged from the study that deployment in the mathematics department was not correlated to the teacher's area of specialisation for successful competence-based curriculum implementation to be achieved. The findings show that the teachers' competences in the school understudy could have a negative impact on student enrolment at university. However, Owusu and Yiboe (2013) argue that teacher's qualification per se cannot determine how effective they become in the classroom, intellectual ability of the teacher has a larger contribution.

Evidence from this study designates the importance of career guidance and consultations from former university students in assisting students when choosing competence-based ALevel mathematics curriculum units that are related to their intended university degree programmes and career aspirations. Furthermore, the results of the study revealed that studying more than one competence-based A-Level mathematics units puts the students at an advantage when it comes to enrolment into mathematics-related degree programmes at university. The results of this study correspond with literature revelation that subject combinations taken by students at A-Level are almost certainly influential for entry requirements to science-based degrees at university (Vidal Rodeiro, 2007).

It emerged from the findings of this study that the university considers Pure Mathematics as the most preferred A-Level mathematics unit when enrolling students in mathematicsrelated degree programmes. Other competence-based A-Level mathematics curriculum units are treated as added advantage. The finding of this study contradicts the claims by Li and $\mathrm{Ni}$, (2011) that mathematics as a subject includes not only Pure Mathematics but also Applied Mathematics, which plays a more important role today. It was also revealed from the results of this study that students studying more mathematical units at A-level puts them at an advantage when enrolling at university. Accordingly, students need more information on subject options and the alternatives open to them to make well-informed choices (Vidal Rodeiro, 2007). This study also established that studying more than one competence-based Advanced Level mathematics curriculum units alone does not make one achieve at university, rather one should incorporate hard work to be successful.

The current study found that the congested timetable hinders students from effectively studying all mathematics units required for university entrance. Hence, the need for proper time management in implementation of competence-based Advanced Level mathematics curriculum effectively (Chinaka, 2019). It also came out from this study that teacher-student ratio in the selected school was too high making it difficult for teachers to adequately prepare students for university enrolment. This finding corroborates with Kavindi's (2014) study in Tanzania which revealed that overcrowded classes is one of the challenges facing implementers of competence-based curriculum. 


\section{CONCLUSION}

From the findings of this study, it can be concluded that teachers are partially competent in teaching all mathematics units in the competence-based Advanced Level mathematics curriculum to prepare students for university enrolment into mathematics-related degree programmes. Additionally, this study concluded that schools are inadequately resourced to fully implement the aforementioned curriculum which negatively impacts the implementation of the competence-based Advanced Level mathematics curriculum and its ability to prepare students for enrolment into university. While some parents as major stakeholders support their children with essential resources others are unable to support their children due to financial constraints or inactive involvement and lack of understanding and knowledge about the curriculum as they think it is a waste of time and resources.

The study also concluded that teachers implementing the competence-based Advanced Level mathematics curriculum are being supervised by superiors who have little or no knowledge on the subject matter. This is leaving the teacher with many unanswered questions about their competences in successful curriculum implementation resulting in them feeling confused and demotivated. The study concluded that Pure Mathematics was more superior to all other competence-based Advanced Level mathematics units and the most preferred unit for universities' entrance enrolment for students wishing to pursue mathematics-related degree programmes. Furthermore, this study concluded that students who do more than one competence-based Advanced Level mathematics units are at an advantage when they get enrolled in mathematics demanding degree programmes at university as they can easily grasp concepts therein.

The other conclusion drawn from this study showed that there is a curriculum mismatch with regards to the competence-based Advanced Level mathematics curriculum and the mathematical components in mathematics-related university degree programmes. Therefore, misinformed students face challenges at university when they meet the concepts they have never studied. Having ascertained that the curriculum offered by schools should match what the university offers, this study concludes that there is lack of effectively disseminated information between the Ministry of Primary and Secondary Education and that of Higher and Tertiary Education, Innovation, Science and Technology Development for stakeholders to positively perceive the competence-based Advanced Level mathematics curriculum. With this communication gap, stakeholders view the curriculum as a rushed project which is there to increase the number of subjects studied at Advanced Level, further financially straining for parents.

\section{Recommendations}

Based on the conclusions highlighted above the researchers make the following recommendations:

- Prior to starting their Advanced Level mathematics studies, students should be oriented and educated on the importance of all mathematics units and how these units influence their university education. The orientation should be organised by career guidance teachers in schools offering different mathematics units at A-Level and involve knowledgeable university experts to explain the pre-requisite units to Mathematics-related university degree programmes.

- The Ministry of Primary and Secondary Education should come up with a syllabus that allows a combination of all mathematics units to level the field for A-Level students intending to pursue mathematics-related degree programmes. 
- The Ministry of Primary and Secondary Education should provide adequate resources to promote the implementation of the competence-based Advanced Level mathematics curriculum in view of students' enrolment at university.

- The Ministry of Primary and Secondary Education should also offer in-service training for teachers such that they will be well equipped and competent to teach all the mathematics units at A-Level hence not restricting student choices because of teachers' knowledge deficiency.

- School supervisors should also be involved in the in-service training such that they are equipped with the new requirements of the competence-based Advanced Level mathematics curriculum hence aiding in proper guidance of both teachers and students.

- Universities should liaise with the Ministry of Primary and Secondary Education and policymakers when it comes to issues of Advanced Level mathematics curriculum review to avoid any curriculum mismatch in the future.

\section{REFERENCES}

Bell, J. F., Malacova, E., \& Shannon, M. (2005). The changing pattern of A level/AS uptake in England. The Curriculum Journal, 16(3), 391-400.

Chinaka, G. (2019). Resourcing the Implementation of Zimbabwe's New Updated Curriculum: Analysis of Rural Primary Schools Experiences in Murewa Nheweyembwa Cluster in Murewa District. Unpublished master's dissertation, Midlands State University, Gweru, Zimbabwe.

Cohen, L., Manion, L., \& Morrison, K. (2011). Research methods in education ( $7^{\text {th }}$ ed.). New York: Routledge.

Darlington, E., \& Bowyer, J. (2016). The Mathematics Needs of Higher Education. Mathematics Today, 52(1), 9.

Esau, H., \& Mpofu, J. (2017). The Preparedness of Primary Schools to implement the Grade 3 New Curriculum in Zimbabwe: Case Study of Bulawayo Metropolitan Primary Schools. European Journal of Social Sciences Studies, 2(4), 1-13.

Froneman, S., \& Hitge, M. (2019). Comparing mathematics knowledge of first year students from three different school curricula. South African Journal of Science, 115(1), 81-87.

Hourigan, M., \& O'Donoghue, J. (2007). Mathematical under-preparedness: the influence of the pre-tertiary mathematics experience on students' ability to make a successful transition to tertiary level mathematics in Ireland. International Journal of Mathematics Education in Science and Technology, 38(4), 461-467.

James, A. (2016). Teaching of Mathematics. Hyderabad: Neelkamal Publication Pvt. Ltd.

Kavindi, A. E. (2014). The implementation of competence based curriculum in certificate teachers colleges in Tanzania: The case of two teachers colleges in Mbeya Region. Unpublished master's thesis, University of Oslo. Retrieved from http://www.duo.uio.no/handle/10852/41289

Kulbir, S. S. (2014). Methodology of Research in Education. New Delhi: Sterling Publishers.

Kulshistha, A. K. (2016). Teaching mathematics. Meerut-25000: R.Lall Book Depot.

Li, Q., \& Ni, K. (2011). Impact of curriculum reform: Evidence of change in classroom practice in Mainland China. International Journal of Research, 50(2), 71-86.

Mack, L. (2010). The philosophical underpinnings of educational research. Polyglossia, 19, 5-11. Retrieved from http://en.apu.ac.jp/rcaps/uploads/fckeditor/publications/polyglossia/Polyglossia_V19_Li ndsay.pdf 
Makanda, G., \& Sypkens, R. (2017). Students Perceptions on the Relevance of High School Mathematics in University Education in South Africa: World Academy of Science, Engineering and Technology. International Journal of Educational and Pedagogical Sciences, 11(11), 2441-2447.

Makunja, G. (2016). Challenges Facing Teachers in Implementing Competence-Based Curriculum in Tanzania: The Case of Community Secondary Schools in Morogoro Municipality. International Journal of Education and Social Science , 3(5), 30-37. Retrieved from http://www.ijessnet.com

Ministry of Primary and Secondary Education. (2015). Curriculum Framework for Primary and Secondary Education 2015-2022. Harare: Government Printers

Nicholas, J., Poladin, L. M., \& Wilson, R. (2015). Mathematics preparation for university: Entry, pathways and impact on performance in first-year science and mathematics subjects. International Journal of Innovation in Science and Mathematics Education, 23(1), 37-51.

Owusu, A. A., \& Yiboe, K. (2013). Teacher Qualifications, Experience and Perceptions as Predictors of Implementation of the Shs French Curriculum in Ghana. International Journal of Education and Research, 1(10), 1-12.

Vidal Rodeiro, C. L. (2007). A Level Subject Choice in England: Patterns of Uptake and Factors Affecting Subject Preferences. Cambridge Assessment, Cambridge.

Wesselink, R. (2010). Comprehensive competence-based vocational education: The development and use of a curriculum analysis and improvement model. Unpublished doctoral thesis Wageningen University, Wageningen, the Netherlands.

Zhuwau, C., \& Shumba, M. (2018). Factors Limiting Smooth Implementation of New Curriculum in Rural Secondary Schools of Zimbabwe: Case Study of Nyanga North Area, Zimbabwe. The International Journal Of Humanities \& Social Studies, 6(11), 198-207. 